\title{
Effect of balloon atrial septostomy on cerebral oxygenation in neonates with transposition of the great arteries
}

\author{
Michelle E. van der Laan', Elise A. Verhagen' ${ }^{1}$, Arend F. Bos' ${ }^{1}$, Rolf M.F. Berger ${ }^{2}$ and Elisabeth M.W. Kooi'
}

BACKGROUND: The aim of this study was to determine the effect of balloon atrial septostomy (BAS) on cerebral oxygenation in neonates with transposition of the great arteries (TGA).

METHODS: In term neonates with TGA, regional cerebral tissue oxygen saturation $\left(\mathrm{r}_{\mathrm{c}} \mathrm{SO}_{2}\right.$ ) was measured using near-infrared spectroscopy (NIRS) for a period of $2 \mathrm{~h}$, before BAS, after $\mathrm{BAS}$, and $24 \mathrm{~h}$ after BAS. In neonates who did not require BAS on clinical grounds, $\mathrm{r}_{\mathrm{c}} \mathrm{SO}_{2}$ was measured within $24 \mathrm{~h}$ of admission and $24 \mathrm{~h}$ later.

RESULTS: BAS was performed in 12 of 21 neonates. $\mathrm{r}_{\mathrm{C}} \mathrm{SO}_{2}$ increased from a median of $42 \%$ (before) to $48 \%$ at $2 \mathrm{~h}$ after BAS $(P<0.05)$, as did transcutaneous arterial oxygen saturation $\left(\mathrm{spO}_{2}\right.$ ) (from $72 \%$ to $85 \%, P<0.01$ ). $\mathrm{r}_{\mathrm{S}} \mathrm{SO}_{2}$ increased further during the next $24 \mathrm{~h}$ (from $48 \%$ to $64 \%, P<0.05$ ), whereas $\mathrm{spO}_{2}$ remained stable. Although beginning from a lower baseline (42 vs. $51 \%, P<0.01$ ), $\mathrm{r}_{\mathrm{c}} \mathrm{SO}_{2}$ was higher in neonates treated with $B A S$, as compared with neonates not treated with BAS, $24 \mathrm{~h}$ after the procedure (64 vs. 58\%, $P<0.05) ; \mathrm{spO}_{2}$ was, however, similar between the two groups.

CONCLUSION: BAS improves cerebral oxygen saturation in neonates with TGA. Complete recovery of cerebral oxygen saturation occurred only $24 \mathrm{~h}$ after BAS.

$\mathbf{T}$ ransposition of the great arteries (TGA) is one of the most common congenital heart diseases requiring neonatal surgical intervention, occurring in 4 neonates per 10,000 live births in The Netherlands (1). The current treatment strategy in TGA consists of the arterial switch operation in the neonatal period. Although mortality is low, neonates with TGA are at risk of impaired neurodevelopmental outcome. Long-term follow-up demonstrates that $30-50 \%$ of school-aged children with TGA show some form of developmental delay, including fine and gross motor delay, impaired visuomotor integration, language and speech difficulties, and behavioral problems (2-5).

Most studies have primarily focused on intraoperative factors as a cause of neonatal brain injury and associated neurodevelopmental delay $(2,4)$. Recently, there has been a shift toward preoperative circumstances and prenatal brain development.
Magnetic resonance imaging studies demonstrate that 25-40\% of neonates with complex congenital heart disease already have evidence of brain injury before surgery (6-9). Severe preoperative hypoxia and acidosis have already been identified as predisposing factors to preoperative brain injury and motor delay in school-aged children with TGA $(3,7)$.

Balloon atrial septostomy (BAS) is an important intervention in neonates with TGA who have severe preoperative hypoxemia despite prostaglandin E1 (PGE1) infusion. BAS aims at increasing systemic oxygenation by improving the mixing of deoxygenated and oxygenated blood at the atrial level. Adverse effects of BAS have also been reported $(10,11)$. As yet, little is known about the direct effect of BAS on the neonatal brain and on cerebral oxygenation in particular.

A noninvasive method of measuring cerebral oxygenation is near-infrared spectroscopy (NIRS) (12-14). By means of NIRS, regional cerebral tissue oxygen saturation $\left(\mathrm{r}_{c} \mathrm{SO}_{2}\right)$, which reflects the venous-weighted oxygen saturation of the underlying cerebral tissue, can be measured. When transcutaneous arterial oxygen saturation $\left(\mathrm{spO}_{2}\right)$ is measured simultaneously, the fractional tissue oxygen extraction (FTOE) can be calculated. Both measures give an impression of cerebral hypoxia and ischemia (12-14). Although previous studies have used NIRS monitoring to study cerebral oxygenation in neonates with congenital heart disease, most of this work has concentrated on intraoperative and postoperative factors $(8,15,16)$. Little is known about the effects of preoperative interventions on cerebral oxygenation in neonates with congenital heart disease and their relationships to neonatal brain injury and neurodevelopmental outcome.

In this study, we determined the effect of BAS on cerebral oxygenation in neonates with TGA by means of NIRS and compared this with the course of cerebral oxygenation in neonates with TGA who did not undergo BAS. We hypothesized that $\mathrm{r}_{\mathrm{c}} \mathrm{SO}_{2}$ would increase shortly after BAS as a result of improved $\mathrm{spO}_{2}$. Furthermore, we hypothesized that $\mathrm{r}_{\mathrm{c}} \mathrm{SO}_{2}$ would be lower at baseline and it would reach similar values after BAS in neonates in need of BAS as compared with neonates who did not need BAS, as a result of adequate mixing of oxygenated and deoxygenated blood.

\footnotetext{
'Division of Neonatology, Beatrix Children's Hospital, University Medical Center Groningen, University of Groningen, Groningen, The Netherlands; ${ }^{2}$ Division of Pediatric Cardiology, Beatrix Children's Hospital, University Medical Center Groningen, University of Groningen, Groningen, The Netherlands. Correspondence: Michelle E. van der Laan (m.e.van.der.laan@umcg.nl)
} 


\section{RESULTS}

\section{Patient Characteristics}

Between December 2007 and June 2011, 31 term neonates with TGA were admitted to our neonatal intensive care unit. Four neonates were not included because of associated cardiac anomalies. In 23 out of the 27 eligible neonates, cerebral oxygenation monitoring was used in preoperative clinical care. In one neonate, cerebral oxygenation monitoring was started only after the BAS procedure had taken place, and in one neonate, data were lost due to technical problems. We were therefore able to include 21 term neonates with TGA with a median gestational age of 39.7 weeks (range: 37.6-42.0), a median birth weight of 3,635 g (range: 2,760-4,480), and a median postnatal age at admission of $1 \mathrm{~d}$ (range: $0-30$ ). Of the neonates with TGA, 12 underwent BAS and 9 did not. Twenty neonates received PGE1 infusion at admission, which was continued during the study period in all neonates. One neonate did not receive PGE1 infusion but underwent a rescue BAS procedure. Five neonates received treatment with nitric oxide because of persistent pulmonary hypertension of the newborn; four of these neonates underwent BAS. In these neonates, nitric oxide was started at $0.5,2,5$, and $12 \mathrm{~h}$ before BAS. Patient characteristics are displayed in Table 1 . The six neonates who were eligible but not included in this study underwent BAS. Except for a higher postnatal age at admission of these neonates, clinical characteristics did not differ from the study group.

\section{Effect of BAS on Cerebral and Arterial Oxygenation}

In all 12 neonates, BAS was performed within $14 \mathrm{~h}$ after admission (median time from admission to BAS: $4 \mathrm{~h}$ (range: 1-14)). Preductal $\mathrm{spO}_{2}$ increased immediately after BAS (from

Table 1. Patient characteristics in the two groups

\begin{tabular}{lccc}
\hline & BAS $(n=12)$ & No BAS $(n=9)$ & $P$ value \\
\hline Gestational age (wk) & $39.7(38.4-41.4)$ & $39.7(37.6-42.0)$ & NS \\
Birth weight (g) & $3,630(2,760-4,480)$ & $3,635(3,175-4,165)$ & NS \\
Male & $9(75)$ & $4(44)$ & NS \\
$\begin{array}{l}\text { Postnatal age } \\
\text { at first r } \text { SO }_{2}\end{array}$ & $1(0-18)$ & $0(0-30)$ & NS \\
measurement (d) & & & \\
Duration of & & $10(3-21)$ & 0.02 \\
hospitalization & $4(1-14)$ & & \\
at first r SO $_{2}$ & & & \\
measurement (h) & & & NS \\
Anatomical diagnosis & & $6(67)$ & \\
$\quad$ TGA, IVS & $9(75)$ & $1(11)$ & \\
TGA, VSD & $2(17)$ & $2(22)$ & NS \\
$\quad$ TGA, CoA, VSD & $1(8)$ & $1(11)$ & NS \\
PPHN & $4(33)$ & $9(100)$ & \\
Use of PGE1 & $11(92)$ & & \\
\hline
\end{tabular}

Data are shown as median (range) or as $n$ (percentage) when appropriate.

$\mathrm{BAS}$, balloon atrial septostomy; CoA, coarctation of the aorta; IVS, intact ventricular septum; NS, not significant; PGE, prostaglandin E1; PPHN, persistent pulmonary hypertension of the newborn; $r \mathrm{SO}_{2}$, regional cerebral tissue oxygen saturation; TGA, transposition of the great arteries; VSD, ventricular septum defect. a median of $72 \%$ before BAS to $85 \% 2 \mathrm{~h}$ after BAS; $P<0.01$, Figure 1a). $\mathrm{r}_{\mathrm{c}} \mathrm{SO}_{2}$ increased as well (from a median of $42 \%$ to $48 \% ; P=0.01$, Figure $1 \mathrm{~b}$ ). $\mathrm{r}_{\mathrm{c}} \mathrm{SO}_{2}$ increased further during the next $24 \mathrm{~h}$ (from $48 \% 2 \mathrm{~h}$ after BAS to $64 \% 24 \mathrm{~h}$ after BAS, $P$ $=0.01$ ), whereas $\mathrm{spO}_{2}$ did not increase further (from $85 \%$ to $86 \%, P=0.33)$. FTOE did not change immediately after BAS (from a median of 0.41 to $0.41 ; P=0.13$, Figure 1c) but did significantly decrease during the next $24 \mathrm{~h}$ (from 0.41 to 0.26 , $P<0.01$ ). The four neonates with persistent pulmonary hypertension of the newborn who underwent BAS showed a similar increment in $\mathrm{spO}_{2}$ and $\mathrm{r}_{\mathrm{c}} \mathrm{SO}_{2}$ and a similar decrease in FTOE after BAS as those of neonates without persistent pulmonary hypertension of the newborn.

\section{Comparison of Cerebral and Arterial Oxygenation Between Groups}

Baseline preductal $\mathrm{spO}_{2}$ was lower in the BAS group as compared with the non-BAS group (median of 72 vs. $87 \%$; $P<$ 0.01 , Figure 1a), as was baseline $\mathrm{r}_{\mathrm{c}} \mathrm{SO}_{2}$ (median of 42 vs. $51 \%$; $P<0.01$, Figure 1b). FTOE at baseline was similar between the two groups (median of 0.41 BAS vs. 0.39 non-BAS; $P=$ 0.31 , Figure $1 \mathrm{c}$ ). After $24 \mathrm{~h}, \mathrm{r}_{\mathrm{c}} \mathrm{SO}_{2}$ was higher (median of 64 vs. $58 \% ; P=0.02$, Figure $1 \mathrm{~b}$ ) and FTOE was lower (0.26 vs. $0.33 ; P=0.04$, Figure 1c) in neonates who underwent BAS as compared with neonates who did not undergo BAS, whereas $\mathrm{spO}_{2}$ was similar between the two groups ( 86 vs. $86 \% ; P=0.51$, Figure 1a).

\section{Clinical Characteristics During the Study Period}

To identify possible confounding factors, we compared clinical characteristics between different time points in the two groups (Table 2). There was a significant reduction in $\mathrm{PCO}_{2}$ immediately after BAS (from a median of 5.8 to $4.3 \mathrm{kPa}, P=0.03$ ). We did not find any significant differences in other clinical characteristics between different time points in the two groups. Furthermore, we compared patient and clinical characteristics at similar time points between the two groups (Tables 1 and 2). Neonates who did not undergo BAS had been hospitalized for longer at the start of NIRS monitoring as compared with neonates who did undergo BAS ( 10 vs. $4 \mathrm{~h} ; P=0.02$, Table 1 ). Furthermore, there were differences in clinical characteristics at baseline between the two groups, with a higher inspired oxygen concentration and a higher serum lactate in neonates who needed BAS (Table 2).

\section{Correlation Between $\mathrm{r}_{c} \mathrm{SO}_{2}$ and $\mathrm{spO}_{2}$}

We investigated the correlation between the simultaneously measured $\mathrm{r}_{\mathrm{c}} \mathrm{SO}_{2}$ and $\mathrm{spO}_{2}$ during the first measurement in all neonates. $\mathrm{r}_{\mathrm{c}} \mathrm{SO}_{2}$ correlated strongly with $\mathrm{spO}_{2}$ (Spearman's $r=$ $0.87, P<0.001)$.

\section{DISCUSSION}

This study in neonates with TGA demonstrated that cerebral tissue oxygen saturation improved shortly after BAS and that $\mathrm{r}_{\mathrm{c}} \mathrm{SO}_{2}$ continued to improve during the next $24 \mathrm{~h}$. Furthermore, it showed that, in our series, cerebral tissue oxygen saturation was 


\section{Articles $\mid$ van der Laan et al.}

a

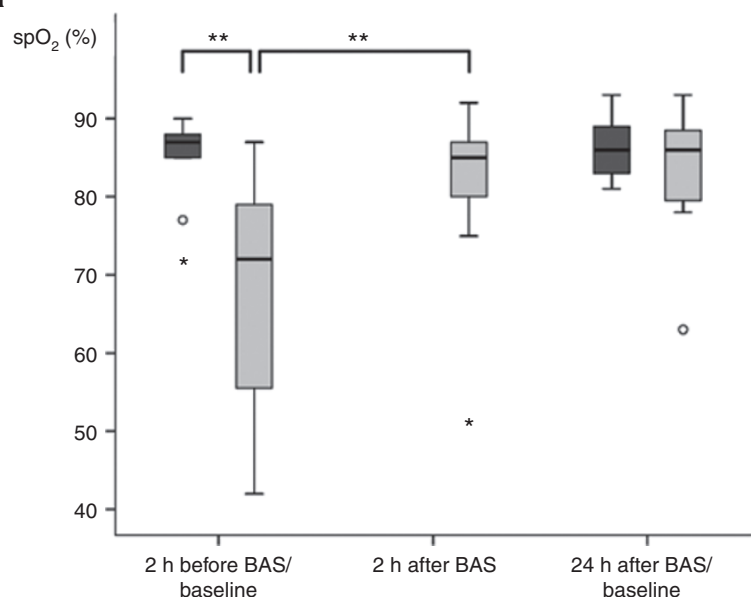

C

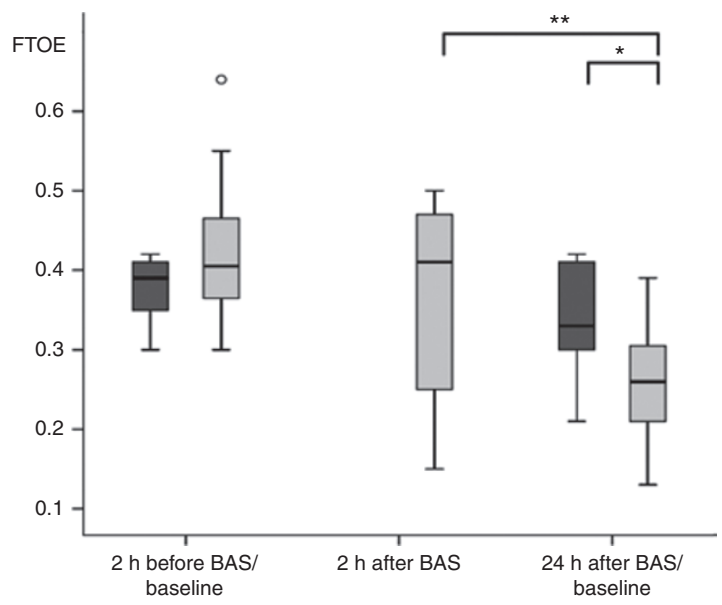

b

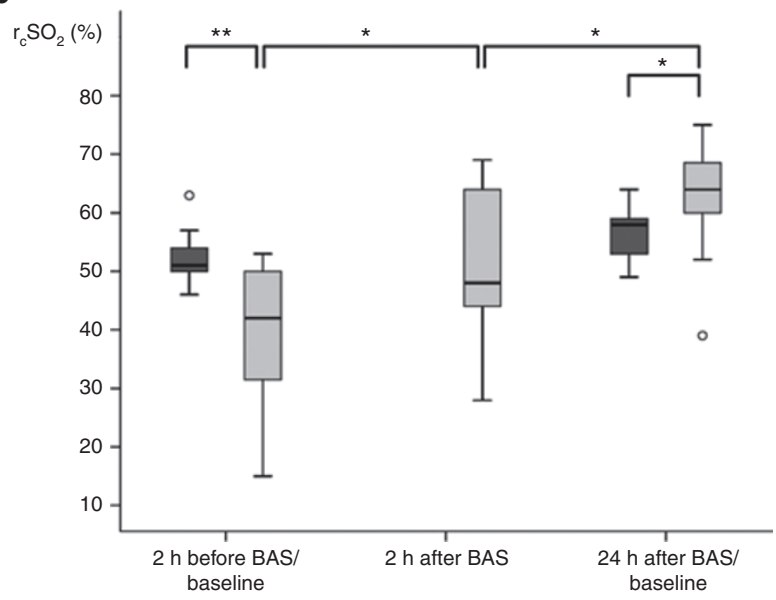

baseline

Figure 1. The course of (a) $\mathrm{spO}_{2^{\prime}}$ (b) $\mathrm{r}_{\mathrm{c}} \mathrm{SO}_{2^{\prime}}$ and (c) FTOE in neonates with TGA who underwent balloon atrial septostomy (BAS) (light gray boxes) vs. neonates with TGA who did not undergo BAS (dark gray boxes). Data are shown in box-and-whisker plots. Open circles and asterisks represent outliers. ${ }^{*} P<0.05,{ }^{* *} P<0.01$. FTOE, fractional tissue oxygen extraction; $\mathrm{r}_{c} \mathrm{SO}_{2^{\prime}}$, regional cerebral tissue oxygen saturation; spO ${ }_{2}$ arterial oxygen saturation; TGA, transposition of the great arteries.

Table 2. Clinical characteristics in the two groups

\begin{tabular}{|c|c|c|c|c|c|}
\hline & \multicolumn{3}{|c|}{$\operatorname{BAS}(n=12)$} & \multicolumn{2}{|c|}{ No BAS $(n=9)$} \\
\hline & $2 \mathrm{~h}$ before BAS & $2 \mathrm{~h}$ after BAS & $24 \mathrm{~h}$ after BAS & Baseline & $24 \mathrm{~h}$ after baseline \\
\hline Ventilatory support (IPPV) & $10(83)$ & $12(100)$ & $9(75)$ & $4(44)$ & $4(44)$ \\
\hline $\begin{array}{l}\text { Mean arterial blood } \\
\text { pressure }(\mathrm{mm} \mathrm{Hg})\end{array}$ & $48(41-74)$ & $44(38-71)$ & $50(40-63)$ & $47(37-66)$ & $50(45-66)$ \\
\hline Lactate (mmol/l) & $3.6(2.5-7.4)^{\mathrm{a}}$ & $2.5(1.5-8.5)$ & $2.1(1.4-3.6)$ & $2.2(1.2-5.1)^{\mathrm{a}}$ & $1.9(1.2-2.3)$ \\
\hline Hemoglobin (mmol/l) & $9.9(8.4-12.7)$ & $10.0(8.7-12.2)$ & $9.9(7.7-12.0)$ & $9.6(8.3-12.2)$ & $9.3(8.3-11.0)$ \\
\hline Sedative treatment (morphine) & $9(75)$ & $12(100)$ & $7(58)$ & $3(33)$ & $3(33)$ \\
\hline $\begin{array}{l}\text { Circulatory support (volume } \\
\text { expansion/inotropes) }\end{array}$ & $4(33)$ & $6(50)$ & $3(25)$ & $2(22)$ & $1(11)$ \\
\hline
\end{tabular}

Data are shown as median (range) or as $n$ (percentage) when appropriate.

BAS, balloon atrial septostomy; IPPV, intermittent positive pressure ventilation.

aSignificant differences were found between the two groups, $P<0.05$ (Mann-Whitney U test). ${ }^{b}$ Significant decrease compared with $2 \mathrm{~h}$ before BAS, $P<0.05$ (Wilcoxon signed-rank test). 
higher at baseline but lower on the second day of admission, in neonates who did not undergo BAS as compared with neonates who did undergo BAS.

Most of these results are in line with our hypothesis. The goal of BAS was to improve mixing of oxygenated and deoxygenated blood at the atrial level and to increase $\mathrm{spO}_{2}$. Given that $\mathrm{r}_{\mathrm{c}} \mathrm{SO}_{2}$ is influenced by cerebral oxygen supply and cerebral oxygen consumption and thus by $\mathrm{spO}_{2}(12-14)$, it was expected that $\mathrm{r}_{\mathrm{c}} \mathrm{SO}_{2}$ would increase immediately after BAS as well. It did, but surprisingly, $\mathrm{r}_{\mathrm{c}} \mathrm{SO}_{2}$ increased further during the next $24 \mathrm{~h}$ after BAS, whereas $\mathrm{spO}_{2}$ remained the same. There are several explanations for this finding. An ongoing increase of $\mathrm{r}_{\mathrm{c}} \mathrm{SO}_{2}$, while $\mathrm{spO}_{2}$ remained stable, can be explained by an increased cerebral blood flow or a decreased cerebral oxygen consumption. First, cerebral blood flow could have been lower shortly after BAS as a result of an autoregulatory response to the increase in $\mathrm{PO}_{2}$ and fall in $\mathrm{PCO}_{2}$ after BAS, which could have led to a delayed improvement in $\mathrm{r}_{c} \mathrm{SO}_{2}$ (17). Second, cerebral oxygen consumption could have been higher shortly after BAS as a result of a possible pre-BAS oxygen deficit. However, a presumed higher postoperative cerebral oxygen extraction in neonates with TGA and a low preoperative $\mathrm{r}_{c} \mathrm{SO}_{2}$ has been described only in neonates undergoing an arterial switch procedure (15) and not in neonates undergoing a procedure such as BAS. Third, when assuming that pre-BAS cerebral oxygenation was low enough to significantly affect cerebral circulation, delayed cerebral hyperemia, which has been well described in infants with hypoxic-ischemic brain injury $(18,19)$, could possibly explain the continuing increase in $\mathrm{r}_{\mathrm{c}} \mathrm{SO}_{2}$. However, these explanations remain highly speculative, given that we do not have direct information about cerebral blood flow or cerebral metabolic rate in our population. The continued improvement in cerebral oxygen saturation could also have been due to factors other than BAS itself. A previous study in preterm neonates reported that cerebral oxygen saturation increases by $\sim 10 \%$ per day in the first $3 \mathrm{~d}$ after birth, possibly as a result of increased cerebral blood flow (20). As 9 of the 12 neonates in our group were younger than $48 \mathrm{~h}$ at the time of BAS, part of the increment in $\mathrm{r}_{\mathrm{c}} \mathrm{SO}_{2}$, which was seen between 2 and $24 \mathrm{~h}$ after BAS, could be a reflection of this increase in cerebral blood flow, extrapolating that such an increase in cerebral blood flow is also present in term neonates.

It has been suggested that a prolonged low pre- and postoperative $\mathrm{r}_{\mathrm{c}} \mathrm{SO}_{2}$ in neonates with congenital heart disease is associated with brain injury and impaired neurodevelopmental outcome. A previous study of cerebral oxygenation in neonates with TGA undergoing an arterial switch operation showed a trend toward a less favorable neurodevelopmental outcome in neonates with a preoperative $\mathrm{r}_{\mathrm{c}} \mathrm{SO}_{2}<35 \%$, as compared with neonates with a higher preoperative $\mathrm{r}_{c} \mathrm{SO}_{2}$ (15). Another study in neonates with hypoplastic left heart syndrome undergoing Norwood 1 palliation showed that a prolonged $\mathrm{r}_{\mathrm{c}} \mathrm{SO}_{2}<45 \%$ in the postoperative period was associated with brain injury as detected on postoperative magnetic resonance imaging scans (16). In our study, the median $\mathrm{r}_{\mathrm{c}} \mathrm{SO}_{2}$ in the BAS group was $42 \%$ before BAS, which means that a considerable proportion of these neonates may have been at risk of developing brain injury. Given that BAS led to an improvement of $\mathrm{r}_{\mathrm{c}} \mathrm{SO}_{2}$ to what are probably more "safe" median values of $48 \%$ at $2 \mathrm{~h}$ after BAS and $64 \%$ at $24 \mathrm{~h}$ after BAS, BAS could be regarded as a neuroprotective intervention in these neonates. In addition, earlier application of BAS could reduce the time of impaired cerebral tissue oxygen saturation and possibly minimize the risk of brain injury in these neonates even more.

Adverse effects of BAS have also been reported. It has been suggested that BAS is a major risk factor for the development of preoperative brain injury, particularly stroke, in neonates with TGA $(10,11)$. Recently, Mukherjee et al. demonstrated that BAS was associated with nearly twice the risk of clinically recognized stroke in 8,681 neonates with TGA (11). However, Applegate and Lim did not find this association in 2,000 children with TGA (21). Furthermore, recent magnetic resonance imaging studies have suggested that decreased arterial oxygenation and the presence of an intact ventricular septum, and not BAS, are associated with preoperative brain injury $(7,22)$. Nevertheless, the risk of thrombosis remains a possible adverse risk factor associated with BAS. In our study, one neonate developed thrombosis of the inferior vena cava following BAS without any clinical signs of stroke.

Our second objective was to compare the course of cerebral oxygenation between neonates who underwent BAS and neonates who did not undergo BAS. In line with our hypothesis, $\mathrm{spO}_{2}$ and $\mathrm{r}_{\mathrm{c}} \mathrm{SO}_{2}$ at baseline were lower in neonates who underwent BAS as compared with neonates who did not undergo BAS. As the neonates in the BAS group had a lower postnatal age at baseline than the neonates who did not undergo BAS, we cannot exclude that part of the difference in $\mathrm{r}_{c} \mathrm{SO}_{2}$ between the two groups might be explained by an increase in cerebral blood flow after birth. The similar FTOE at baseline, however, implies that the balance between cerebral oxygen demand and cerebral oxygen delivery did not differ between both groups. In contrast to our hypothesis, neonates who underwent BAS had a higher $\mathrm{r}_{\mathrm{c}} \mathrm{SO}_{2}$, and lower FTOE, $24 \mathrm{~h}$ after BAS as compared with neonates who did not undergo BAS, whereas $\mathrm{spO}_{2}$ was similar between the two groups. We offer three explanations for this finding. First, clinical management differed between groups, with more infants in the BAS group being ventilated and receiving morphine, although this did not reach statistical significance. Previously, in preterm neonates, treatment with morphine has been associated with an increased cerebral perfusion (23). Second, assuming that pre-BAS cerebral oxygenation was low enough to significantly affect cerebral circulation in the BAS group, cerebral perfusion could have been higher in the neonates who underwent BAS as compared with the neonates who did not undergo BAS as described previously. Third, cerebral perfusion may increase through higher right-ventricular output, leading to higher preductal and thus cerebral blood flow, on the basis of improved interatrial mixing as a result of BAS. In our study, we did not measure cerebral blood flow or ventricular output, so these explanations remain speculative.

Although baseline $\mathrm{spO}_{2}$ correlated strongly with $\mathrm{r}_{\mathrm{c}} \mathrm{SO}_{2}$, preoperative NIRS monitoring could, in theory, help to identify 
neonates with TGA with low cerebral oxygen saturation earlier, especially those neonates in whom $\mathrm{spO}_{2}$ is quite normal but cerebral oxygen saturation is impaired. In our series, we identified one such neonate, with TGA and a ventricular septum defect, who had a reasonably normal $\mathrm{spO}_{2}$ of $77 \%$ but a very low $\mathrm{r}_{\mathrm{c}} \mathrm{SO}_{2}$ of $35 \%$. However, concerns have been raised regarding the accuracy and precision of $\mathrm{r}_{c} \mathrm{SO}_{2}$ as measured by NIRS. Previous studies have described a high replacement variability with limits of agreement of up to $18 \%(24-26)$. For example, in a recent study performed in term infants, the limits of agreement for the differences of $\mathrm{r}_{\mathrm{c}} \mathrm{SO}_{2}$ measured simultaneously at four different brain regions were between $\pm 12 \%$ and $\pm 16 \%$ (26). Therefore, one should be careful when making clinical decisions regarding individual patients on the basis of absolute NIRS values. Repeatability of the $\mathrm{r}_{\mathrm{c}} \mathrm{SO}_{2}$ measurements, using the same device as we did, is reported to be more stable, with limits of agreement $<6 \%$ (27). In our center, repeatability of the $\mathrm{r}_{\mathrm{c}} \mathrm{SO}_{2}$ measurements after refixation of the optode, and allowing $10 \mathrm{~min}$ to stabilize $\mathrm{r}_{\mathrm{c}} \mathrm{SO}_{2}$, was similar with a mean difference of $4.5 \%$ (range $1-8 \%$ between three consecutive measurements of the same patient (E.A.V. and A.F.B., unpublished data)). This variability of repeated measurements in the same patient seems lower than the differences that we have found within groups.

We recognize some limitations of this study. First, this was not a randomized clinical trial of neonates with TGA on treatment with or without BAS. Given that BAS was performed on clinical grounds, differences in the course of $\mathrm{r}_{\mathrm{c}} \mathrm{SO}_{2}$ may be dependent on our BAS policy. Second, we included only a small number of neonates, which could explain the lack of statistical significance in clinical characteristics that was found. Third, only 21 neonates with TGA were included of the 27 who were admitted to our ward and were eligible, partly as a result of the random use of cerebral oxygenation monitoring on our ward before 2009. However, there were hardly any clinically significant differences between neonates who were and were not included in this study. Finally, we did not perform pre- or postoperative magnetic resonance imaging scans routinely. We were, therefore, not able to identify significant brain injury related to low $\mathrm{r}_{\mathrm{c}} \mathrm{SO}_{2}$ values in our group.

\section{Conclusion}

BAS improves cerebral oxygen saturation in neonates with TGA whose oxygenation may be impaired and might therefore be considered as a neuroprotective intervention in these neonates. Future long-term outcome studies are warranted to determine predictive values of cerebral oxygen saturation and extraction in neonates with TGA on neurocognitive development.

\section{METHODS}

\section{Patients}

In this retrospective observational cohort study, all term neonates with dextro-TGA admitted to the neonatal intensive care unit of the University Medical Center Groningen between December 2007 and June 2011 were considered for inclusion. Only neonates in whom preoperative cerebral oxygenation monitoring was used were included. Neonates with associated cardiac anomalies other than a ventricular septum defect, an atrial septum defect, or a coarctation of the aorta were not included. The study was approved by the ethical review board of the University Medical Center Groningen. Informed parental consent was obtained in all cases.

\section{Protocol}

Anatomical diagnosis of TGA was confirmed by transthoracic echocardiography. Preoperative cerebral oxygenation monitoring in neonates with TGA admitted to our neonatal intensive care unit has only become standard care since 2009. Before 2009, cerebral oxygenation monitoring was used randomly, dependent on the availability of the cerebral oxygenation monitoring device. Cerebral oxygenation monitoring was started as soon as possible after admission and was continued for as long as clinically indicated, but for at least $48 \mathrm{~h}$. Clinical characteristics were collected prospectively during the study period.

\section{BAS}

The decision to perform BAS was made by the attending pediatric cardiologist within $24 \mathrm{~h}$ of admission and was based on echocardiographic evaluation of interatrial mixing, with inadequate mixing defined as restrictive flow over the atrial septum and/or bulging of the septum, in combination with clinical features such as persistent hypoxemia or acidosis despite PGE1 infusion. All BAS procedures were performed at the neonatal intensive care unit as a bedside procedure under echocardiographic guidance. All neonates were sedated and mechanically ventilated before BAS. A size 7 French Fogarty balloon septostomy catheter was introduced into the femoral or umbilical vein. Heparin (100 IU/kg) was administered routinely. BAS was considered successful when there was unrestricted flow over the atrial septum at the end of the procedure, which was achieved in all neonates included in the study.

\section{Cerebral Oxygenation Monitoring}

For cerebral oxygenation monitoring, we used an INVOS $5100 \mathrm{C}$ near-infrared spectrometer (Somanetics, Troy, MI) and pediatric SomaSensors (Somanetics) to continuously measure $\mathrm{r}_{c} \mathrm{SO}_{2}$. The SomaSensor was placed on the left frontoparietal side of the neonate's head and was held in place with an elastic bandage. Five minutes were allowed for stabilization of the measurement. Simultaneously, we continuously measured the preductal transcutaneous arterial oxygen saturation by pulse oximetry of the right hand. All $\mathrm{r}_{\mathrm{c}} \mathrm{SO}_{2}$ and $\mathrm{spO}_{2}$ measurements were stored at 5 -min intervals for off-line analysis during the study period. To investigate the balance between cerebral oxygen delivery and cerebral oxygen consumption, the FTOE was calculated as $\left(\mathrm{spO}_{2}-\mathrm{r}_{\mathrm{c}} \mathrm{SO}_{2}\right) / \mathrm{spO}_{2}$. As FTOE is less dependent on changes in $\mathrm{spO}_{2}$ than $\mathrm{r}_{\mathrm{c}} \mathrm{SO}_{2}$, FTOE serves as a better marker for ischemic hypoxia than $\mathrm{r}_{\mathrm{c}} \mathrm{SO}_{2}(28)$. To assess the effect of BAS on cerebral and arterial oxygenation, we calculated mean values of $\mathrm{r}_{\mathrm{c}} \mathrm{SO}_{2}, \mathrm{spO}_{2}$, and FTOE immediately before BAS, if possible for a 2 -h period but at least for $20 \mathrm{~min}$, and $2 \mathrm{~h}$, and $24 \mathrm{~h}$ after BAS for a 2 -h period. In neonates who did not undergo BAS, mean values of $\mathrm{r} \mathrm{SO}_{2}, \mathrm{spO}_{2}$, and FTOE were calculated twice for a 2 -h period: once within $24 \mathrm{~h}$ of admission and once $24 \mathrm{~h}$ after the first measurement. Although measurements were performed continuously during the first days after birth in all neonates, the sensor was removed daily for a few minutes to monitor possible skin irritation. To minimize replacement variability, the position of the sensor was marked before replacement and $5 \mathrm{~min}$ were allowed for stabilization of the measurement after replacement.

\section{Clinical Characteristics}

Clinical characteristics that could influence cerebral oxygenation were collected from the patients' medical charts or were registered during the study period. These data included gestational age, birth weight, gender, postnatal age, anatomical diagnosis, ventilatory status, blood pressure, blood gas values, and hemoglobin and lactate concentrations. Furthermore, treatment with PGE1 and nitric oxide because of persistent pulmonary hypertension of the newborn was documented (29).

\section{Statistical Analysis}

We classified the infants into two groups: one consisting of neonates who underwent BAS and the other of neonates who did not undergo BAS. The repeated measurements of $\mathrm{r}_{\mathrm{C}} \mathrm{SO}_{2}, \mathrm{spO}_{2}$, and FTOE and other clinical characteristics in the BAS group were analyzed using the Wilcoxon signed-rank test. Differences in the course of $\mathrm{r}_{\mathrm{c}} \mathrm{SO}_{2}, \mathrm{spO}_{2}$, 
and FTOE between the two groups at different time points were analyzed using the Mann-Whitney U test. To analyze differences of clinical parameters between the two groups, we used the Mann-Whitney $\mathrm{U}$ test for continuous data and Fisher's exact test or $\chi^{2}$-test for categorical data. Finally, we determined the correlation between $\mathrm{spO}_{2}$ and $\mathrm{r} \mathrm{SO}_{2}$ during the first measurement using Spearman's rank order correlation test. We did not exclude outliers from our analyses, given that our study group was relatively small. SPSS 16.0 (SPSS, Chicago, IL) was used for statistical analysis. A $P$ value $<0.05$ was considered significant.

\section{ACKNOWLEDGMENT}

This study was part of the Research School for Behavioral and Cognitive Neurosciences, University of Groningen, The Netherlands.

\section{STATEMENT OF FINANCIAL SUPPORT}

M.E.v.d.L. was financially supported by a grant from the Junior Scientific Masterclass of the University of Groningen.

Disclosure: The authors declared no conflict of interest.

\section{REFERENCES}

1. Eurocat Northern Netherlands. Prevalence of congenital malformations in the Northern Netherlands 1981-2007. Updated 2009. (http://www. eurocat-network.eu/accessprevalencedata/prevalencetables).

2. Majnemer A, Limperopoulos C, Shevell M, Rosenblatt B, Rohlicek C, Tchervenkov C. Long-term neuromotor outcome at school entry of infants with congenital heart defects requiring open-heart surgery. J Pediatr 2006;148:72-7.

3. Hövels-Gürich HH, Seghaye MC, Schnitker R, et al. Long-term neurodevelopmental outcomes in school-aged children after neonatal arterial switch operation. J Thorac Cardiovasc Surg 2002;124:448-58.

4. Bellinger DC, Wypij D, duPlessis AJ, et al. Neurodevelopmental status at eight years in children with dextro-transposition of the great arteries: the Boston Circulatory Arrest Trial. J Thorac Cardiovasc Surg 2003;126: $1385-96$.

5. Hövels-Gürich HH, Konrad K, Wiesner M, et al. Long term behavioural outcome after neonatal arterial switch operation for transposition of the great arteries. Arch Dis Child 2002;87:506-10.

6. Mahle WT, Tavani F, Zimmerman RA, et al. An MRI study of neurological injury before and after congenital heart surgery. Circulation 2002;106:12 Suppl 1:I109-14.

7. Petit CJ, Rome JJ, Wernovsky G, et al. Preoperative brain injury in transposition of the great arteries is associated with oxygenation and time to surgery, not balloon atrial septostomy. Circulation 2009;119:709-16.

8. Andropoulos DB, Hunter JV, Nelson DP, et al. Brain immaturity is associated with brain injury before and after neonatal cardiac surgery with highflow bypass and cerebral oxygenation monitoring. J Thorac Cardiovasc Surg 2010;139:543-56.

9. Miller SP, McQuillen PS, Hamrick S, et al. Abnormal brain development in newborns with congenital heart disease. N Engl J Med 2007;357:1928-38.

10. McQuillen PS, Hamrick SE, Perez MJ, et al. Balloon atrial septostomy is associated with preoperative stroke in neonates with transposition of the great arteries. Circulation 2006;113:280-5.

11. Mukherjee D, Lindsay M, Zhang Y, et al. Analysis of 8681 neonates with transposition of the great arteries: outcomes with and without Rashkind balloon atrial septostomy. Cardiol Young 2010;20:373-80.

12. Wyatt JS, Cope M, Delpy DT, Wray S, Reynolds EO. Quantification of cerebral oxygenation and haemodynamics in sick newborn infants by near infrared spectrophotometry. Lancet 1986;2:1063-6.
13. Verhagen EA, Keating P, ter Horst HJ, Martijn A, Bos AF. Cerebral oxygen saturation and extraction in preterm infants with transient periventricular echodensities. Pediatrics 2009;124:294-301.

14. Naulaers G, Meyns B, Miserez M, et al. Use of tissue oxygenation index and fractional tissue oxygen extraction as non-invasive parameters for cerebral oxygenation. A validation study in piglets. Neonatology 2007;92:120-6.

15. Toet MC, Flinterman A, Laar I, et al. Cerebral oxygen saturation and electrical brain activity before, during, and up to 36 hours after arterial switch procedure in neonates without pre-existing brain damage: its relationship to neurodevelopmental outcome. Exp Brain Res 2005; 165:343-50.

16. Dent CL, Spaeth JP, Jones BV, et al. Brain magnetic resonance imaging abnormalities after the Norwood procedure using regional cerebral perfusion. J Thorac Cardiovasc Surg 2005;130:1523-30.

17. Vanderhaegen J, Naulaers G, Vanhole C, et al. The effect of changes in tPCO2 on the fractional tissue oxygen extraction-as measured by nearinfrared spectroscopy-in neonates during the first days of life. Eur J Paediatr Neurol 2009;13:128-34.

18. Archer LN, Levene MI, Evans DH. Cerebral artery Doppler ultrasonography for prediction of outcome after perinatal asphyxia. Lancet 1986;2:1116-8.

19. Meek JH, Elwell CE, McCormick DC, et al. Abnormal cerebral haemodynamics in perinatally asphyxiated neonates related to outcome. Arch Dis Child Fetal Neonatal Ed 1999;81:F110-5.

20. Naulaers G, Morren G, Van Huffel S, Casaer P, Devlieger H. Measurement of tissue oxygenation index during the first three days in premature born infants. In: Wilson D, ed. Oxygen Transport to Tissue XXIII, vol. 510. New York, NY: Kluwer Academic/Plenum Publishers, 2003:379-383.

21. Applegate SE, Lim DS. Incidence of stroke in patients with d-transposition of the great arteries that undergo balloon atrial septostomy in the University Healthsystem Consortium Clinical Data Base/Resource Manager. Catheter Cardiovasc Interv 2010;76:129-31.

22. Beca J, Gunn J, Coleman L, et al. Pre-operative brain injury in newborn infants with transposition of the great arteries occurs at rates similar to other complex congenital heart disease and is not related to balloon atrial septostomy. J Am Coll Cardiol 2009;53:1807-11.

23. van Alfen-van der Velden AA, Hopman JC, Klaessens JH, Feuth T, Sengers RC, Liem KD. Effects of midazolam and morphine on cerebral oxygenation and hemodynamics in ventilated premature infants. Biol Neonate 2006;90:197-202.

24. Sorensen LC, Greisen G. Precision of measurement of cerebral tissue oxygenation index using near-infrared spectroscopy in preterm neonates. J Biomed Opt 2006;11:054005.

25. Dullenkopf A, Kolarova A, Schulz G, Frey B, Baenziger O, Weiss M. Reproducibility of cerebral oxygenation measurement in neonates and infants in the clinical setting using the NIRO 300 oximeter. Pediatr Crit Care Med 2005;6:344-7.

26. Wijbenga RG, Lemmers PM, van Bel F. Cerebral oxygenation during the first days of life in preterm and term neonates: differences between different brain regions. Pediatr Res 2011;70:389-94.

27. Lemmers PM, Toet MC, van Bel F. Impact of patent ductus arteriosus and subsequent therapy with indomethacin on cerebral oxygenation in preterm infants. Pediatrics 2008;121:142-7.

28. van Bel F, Lemmers P, Naulaers G. Monitoring neonatal regional cerebral oxygen saturation in clinical practice: value and pitfalls. Neonatology 2008;94:237-44.

29. Roofthooft MT, Bergman KA, Waterbolk TW, Ebels T, Bartelds B, Berger RM. Persistent pulmonary hypertension of the newborn with transposition of the great arteries. Ann Thorac Surg 2007;83:1446-50. 